\title{
Lutas e a formação de professores de educação física: reflexos na atuação profissional de docentes da rede municipal de educação de Belém - PA
}

\author{
Fights and the formation of physical education teachers: reflections on the professional activity \\ of teachers of the municipal education network of Belém - PA
}

DOI: $\underline{\text { http://dx.doi.org/10.36453/2318-5104.2018.v16.n1.p79 }}$

\author{
Marcio Antonio Raiol dos Santos, Pedro Paulo Souza Brandão
}

Universidade Federal do Pará (UFPA)

\begin{abstract}
RESUMO
Este estudo tem como principal objetivo investigar os reflexos da formação de professores de educação física na atuação profissional de docentes que trabalham o conhecimento das Lutas na Rede Municipal de Educação de Belém-PA. Foi configurado com base em uma pesquisa de campo de natureza qualitativa, que teve como participantes todos os professores de Educação Física da Rede Municipal de Educação de Belém-PA que atuam em escolas que atendem aos anos finais do Ensino Fundamental. Como instrumento de coleta de dados foi utilizado formulário e, como técnica de análise dos dados, optamos pela Análise de Conteúdo. Os resultados revelaram que: a) a maioria dos professores teve contato com o conteúdo das Lutas na sua formação acadêmica por meio de disciplinas de forma fragmentada em modalidades sem correlação entre estas e com perspectiva técnica; b) Os docentes tratam pedagogicamente o conteúdo Lutas de três formas: i) ensino fragmentado de forma autônoma (modalidades específicas ensinadas pelos docentes); ii) ensino fragmentado de forma dependente (modalidades específicas ensinadas por especialistas/lutadores); iii) ensino global (princípios comuns das Lutas didatizados de forma lúdica); c) o aprendizado de disciplina e valores sociais são os principais benefícios atribuídos ao conteúdo pelos professores. Com isso, podemos concluir que a falta de domínio de ferramentas didático-metodológicas para o ensino das Lutas pelos docentes é reflexo da forma como estes tiveram contato com esse conteúdo na própria formação universitária, revelando a deficiência desta e a necessidade de qualificá-la para refletir positivamente na atuação profissional dos professores na escola.
\end{abstract}

PALAVRAS-CHAVE: Formação de professores; Educação Física escolar; Lutas.

\section{ABSTRACT}

This study aims to investigate the reflexes of the formation of physical education teachers in the professional work of teachers that work the knowledge of the fights in the Municipal Education Network of Belém-PA. It was configured based on a field research with qualitative nature that had as participants all the physical education teachers of the Municipal Education Network of Belém-PA who works in schools that attend the final years of elementary school. As a data collection instrument, a form was used and, as a data analysis technique, we opted for content analysis. The results revealed that: a) most of the teachers had contact with the content of the fights in the formation through disciplines, in a fragmented way in modalities without correlation between these and, with a technical perspective; b)Teachers treat pedagogically the content fights in three ways: i) fragmented teaching by autonomous way (specific modalities taught by teachers); ii) fragmented teaching in a dependent way (specific modalities taught by specialists/fighters); iii) global education (common principles of the fights didatized in a ludic way); c) learning of discipline and social values are the main benefits attributed to content by teachers. With this, we can conclude that the lack of domain of didactic-methodological tools for the teaching of the fights, by the teachers, is a reflection of the way in which they had contact with this content in the formation, revealing its deficiency and the need to qualify it, to reflect positively on the professional performance of teachers in the school.

KEYWORDS: Teacher formation; school physical education; fights. 


\section{INTRODUÇÃO}

Este artigo tem como principal objetivo investigar os reflexos da formação de professores de Educação Física na atuação profissional de docentes que trabalham o conhecimento das lutas na Rede Municipal de Educação de Belém-PA. Para atingir esse fim, elaboramos outros objetivos: a) verificar se os docentes tiveram contato com as lutas em sua formação e de que forma se deu esse contato; b) identificar de que forma esses docentes trabalham o conteúdo das lutas nas aulas de educação física; c) identificar quais são os benefícios que os professores destacam no ensino das lutas na educação física escolar.

A motivação para a realização deste estudo surgiu da inquietação de compreender como os professores da Rede Municipal de Educação de Belém (PA) tratam pedagogicamente o conhecimento das lutas e quais são os reflexos de sua formação, tendo como pressupostos a importância intrínseca desse conteúdo na formação discente e sua relação com a "hegemonia" de outros conteúdos, como o esporte, como aponta a literatura especializada.

Sobre o que diz a literatura, Nascimento e Almeida (2007) e Corrêa, Queiroz e Pereira (2010) apontam fragilidades na formação de professores, que acabam se refletindo na atuação dos mesmos, pelo fato de os cursos de formação superior em Educação Física estarem baseados no "saber fazer para ensinar", o que resulta em uma formação essencialmente técnica. Outra pesquisa que destaca esta realidade é a de Gomes (2014). O autor revelou que os alunos dos cursos de graduação aprendem a lutar, mas não aprendem como ensinar os fundamentos das lutas para os educandos na escola, fato que ocorre pela metodologia de ensino dos docentes do ensino superior focar o ensinamento de gestos técnicos e, com isso, não dão aos graduandos aporte didático-metodológico para que estes trabalhem as lutas na escola a contento.

Silva (2013) confirma o que foi relatado por Gomes (2014), ao tentar compreender o processo de sistematização do conhecimento das lutas na formação docente. Sua pesquisa apresenta como proposta para transformação dessa realidade uma abordagem das lutas em diversos eixos, tais como: a reflexão, a pesquisa como elemento estruturante do ensino e a preocupação com a sistematização do conteúdo.

No entanto, esse não é um problema apenas da prática pedagógica dos docentes da formação universitária, mas do próprio currículo oficial. O estudo de Araújo (2015) demonstra essa problemática, relatando uma abordagem restritiva do conhecimento, em favorecimento do rendimento físico e dos interesses de mercado nos projetos político-pedagógicos dos cursos de formação superior, resoluções e ementas das disciplinas voltadas para o conhecimento das lutas.

Outro fator foi constatado por Mendonça et al. (2013), ao identificarem que as lutas são tratadas de forma optativa na maioria das instituições que oferecem a licenciatura em Educação Física. Além do mais, verificou-se que, quando esse conhecimento é ofertado, acontece de forma fragmentada em modalidades.

No contexto do nosso estudo, a cidade de Belém possui duas instituições públicas e duas privadas com o curso de Licenciatura em Educação Física. No caso das duas públicas, a Universidade Federal do Pará (UFPA) e a Universidade do Estado do Pará (UEPA), são as que formaram os professores participantes deste estudo, conforme os mesmos informaram no campo de dados pessoais do formulário de pesquisa. Sabendo disso, destacamos a pesquisa de Brandão (2015), que analisou os currículos dos cursos de Educação Física dessas duas universidades e constatou a fragmentação do ensino citada por Mendonça et al. (2013) e as limitações quanto à prática pedagógica dos docentes da formação superior, no que tange ao ensino das disciplinas que dialogam com o conhecimento das lutas.

Tais argumentos refletem negativamente na atuação dos professores de educação física na educação básica, pois estes tendem a não traduzir o ensino das lutas na escola, da forma como deveriam fazê-lo. Em vista do que foi revelado pela literatura, especialmente por Brandão (2015), que investigou o contexto local do estudo, investigamos a realidade dos docentes da Rede Municipal de Educação de Belém (PA) com o intuito de averiguar os reflexos da formação dos professores em sua atuação profissional, quanto ao ensino das lutas na escola.

Esse conhecimento tem sua importância no âmbito escolar porque, além de ser uma das práticas corporais construídas historicamente pela humanidade, configurando-se como um dos elementos da cultura corporal, possui uma série de benefícios, como o desenvolvimento motor (LOPES; KERR, 2015), o desenvolvimento humano e social (RODRIGUES et al., 2017), a possibilidade do trato e a problematização de temáticas como as 
questões de gênero, violência e diversidade cultural (BRANDÃO, 2018). Portanto, um conhecimento com tantos benefícios necessita de um trato pedagógico que permita o ensino dessas práticas corporais com qualidade. Sendo assim, os docentes devem possuir domínio das ferramentas didático-metodológicas para tal fim, pois é por meio da formação acadêmica que o acesso a essas ferramentas deve ser realizado. Do contrário, uma formação fragilizada pode refletir negativamente na atuação docente na escola.

\section{MÉTODOS}

Este estudo é oriundo de uma pesquisa de campo (FONSECA, 2002) de natureza qualitativa, pois considera o universo de significados que envolve atitudes, valores, crenças e motivações (MINAYO et al., 2002). Os procedimentos realizados fizeram parte da primeira etapa de uma pesquisa de Dissertação de Mestrado, a qual foi aprovada pelo Parecer no 2.260.608, do Comitê de Ética em Pesquisa (CEP), credenciado na Comissão Nacional de Ética em Pesquisa (CONEP).

Para a coleta de dados, realizou-se a aplicação de formulário, que consiste em um instrumento de coleta que se caracteriza por ser uma lista formal de perguntas preenchidas pelo próprio investigador mediante as respostas dos pesquisados em um encontro face a face com os mesmos (MARCONI; LAKATOS, 2010). A coleta foi realizada com todos (100\%) os docentes de educação física (vinte sujeitos) da Rede Municipal de Educação de Belém (PA) atuantes em escolas que atendem aos anos finais do ensino fundamental. Tal escolha se deve ao fato de o conteúdo de lutas estar previsto nesse nível de ensino na Base Nacional Comum Curricular (BNCC) (BRASIL, 2017) e, anteriormente, nos Parâmetros Curriculares Nacionais (BRASIL, 1997). Os docentes aceitaram participar da pesquisa por meio do Termo de Consentimento Livre e Esclarecido (TCLE).

Os formulários foram lidos para os pesquisados e as respostas foram imediatamente transcritas pelos pesquisadores. As perguntas do formulário foram divididas em três blocos:

1- Questões de formação: há quanto tempo você é formado na área? Em qual instituição você se formou? Você possui pós-graduação? Caso sim, qual?

2- Questões profissionais e dados pessoais: Qual é sua idade? Há quanto tempo você trabalha na rede? Em quantas escolas você trabalha?

3- Questões sobre as lutas: Você teve contato com o conteúdo lutas durante a sua formação acadêmica? Caso sim, como? Você já utilizou/utiliza o conteúdo das lutas durante as aulas? Caso sim, como? Quais são os benefícios que você acha que o conteúdo lutas proporciona aos alunos?

Como critério de seleção, participariam da análise principal os sujeitos que, em uma primeira análise realizada para identificá-los, afirmaram trabalhar com lutas nas aulas de Educação Física. Assim, dos 20 (vinte) sujeitos iniciais somente 12 (doze) foram selecionados para a segunda análise desse estudo.

A análise de conteúdo (BARDIN, 1977) foi escolhida como instrumento para realização do tratamento dos formulários. A análise foi realizada com os seguintes passos:

1- Com o objetivo de apresentar um perfil dos docentes, o bloco das questões de formação acadêmica e questões profissionais e dados pessoais foram agrupados em um único quadro (Quadro 1), no qual cada item do perfil foi transformado em uma categoria de acordo com as peculiaridades dos sujeitos;

2- 0 bloco das questões sobre as lutas foi organizado no quadro 2, com o objetivo de identificar as respostas em comum e a frequência destas para elencar categorias;

3- As categorias do quadro 2 foram correlacionados com o perfil do Quadro 1, para fins de identificar novas categorias que possibilitem a discussão dos reflexos da formação dos professores em sua atuação profissional quanto ao trato do conhecimento com as lutas.

\section{RESULTADOS E DISCUSSÃO}

A cidade de Belém, capital do estado do Pará, fica localizada na região Norte do Brasil, configura-se como uma das principais cidades da região amazônica e possui aproximadamente 1.452.275 habitantes, com uma 
taxa de escolarização de 96,1\% (IBGE, 2017). A Rede Municipal de Educação da cidade é regida pela Secretaria Municipal de Educação (SEMEC), que possui cerca de 60 (sessenta) escolas-sede com ensino fundamental.

Para contemplar tal demanda, aproximadamente 120 professores de educação física atendem a essas escolas, dos quais apenas 20 trabalham com turmas dos anos finais do ensino fundamental. Após a aplicação de formulário com esses sujeitos, identificamos que 12 deles trabalham as lutas como conteúdo da educação física. Em nosso estudo, colocaremos em evidência o resultado da análise das respostas desse grupo para investigar como vem se dando o trato com o conhecimento das lutas na educação física nos anos finais do ensino fundamental.

O Quadro 1 explicita as respostas dos professores referentes às questões de formação acadêmica, profissionais e dados pessoais, identificando o perfil dos professores que trabalham com as lutas na Rede Municipal de Educação de Belém. Para obedecer os princípios éticos, ocultamos os nomes dos sujeitos para garantir o anonimato dos participantes da pesquisa e substituímos cada nome pelo termo "professor", para os do sexo masculino, e pelo termo "professora", para os do sexo feminino, seguido de uma numeração em ordem crescente de 1 a 12 .

Quadro 1. Respostas das questões de formação acadêmica, profissionais e dados pessoais.

\begin{tabular}{|c|c|c|c|c|c|}
\hline Sujeito & $\begin{array}{l}\text { Idade } \\
\text { (anos) }\end{array}$ & $\begin{array}{c}\text { Tempo de } \\
\text { formação } \\
\text { (anos) }\end{array}$ & $\begin{array}{c}\text { Tempo de } \\
\text { serviço } \\
\text { (anos) }\end{array}$ & Pós-graduação & $\begin{array}{c}\text { Número de } \\
\text { escolas que } \\
\text { trabalha }\end{array}$ \\
\hline Professor 1 & 58 & 36 & 27 & Especialização & 1 \\
\hline Professora 2 & 32 & 11 & 10 & Especialização & 1 \\
\hline Professor 3 & 28 & 6 & 3 & Não & +3 \\
\hline Professora 4 & 41 & 17 & 16 & Especialização & 3 \\
\hline Professor 5 & 46 & 21 & 19 & Especialização & +3 \\
\hline Professora 6 & 39 & 17 & 3 & Especialização & 1 \\
\hline Professora 7 & 35 & 11 & 10 & Especialização & 2 \\
\hline Professora 8 & 35 & 13 & 3 & Especialização & 3 \\
\hline Professora 9 & 53 & 30 & 18 & Especialização & 1 \\
\hline Professora 10 & 48 & 25 & 21 & Especialização & 1 \\
\hline Professor 11 & 48 & 19 & 17 & Especialização & 2 \\
\hline Professora 12 & 29 & 6 & 5 & Especialização & 1 \\
\hline
\end{tabular}

Fonte: quadro produzido pelos autores a partir da coleta de dados realizada em 2017.

O Quadro 1 nos permite traçar um perfil dos professores que trabalham as lutas. O primeiro indicativo visível mostra que quase todos, à exceção de um, possuem pós-graduação (especialização latu-sensu), o que pode indicar a importância da formação continuada para que os professores possam se qualificar e desenvolver os conteúdos da educação física, especialmente as lutas, pois estudos como o de Rufino (2012) apontam que as lutas são um conteúdo pouco explorado na educação física escolar e que um dos fatores que contribuem para esse cenário são as fragilidades na formação dos professores, tanto inicial, quanto continuada.

Os outros fatores importantes identificados foram estes: a maioria (dois terços) dos professores são do sexo feminino. Além disso, metade dos sujeitos tem até 10 anos de tempo de serviço, independentemente da idade que possuem. Quanto ao fator idade, metade dos professores tem mais de 40 anos. Esse perfil será importante para podermos relacioná-lo com a experiência desses professores com as lutas e a forma como eles a sistematizam em suas aulas, ao cruzarmos com as respostas das questões sobre as lutas, expostas no Quadro 2.

Como podemos observar, apenas uma professora não teve contato com as lutas na sua formação inicial. Vale ressaltarmos que todos os pesquisados tiveram sua formação inicial em instituições públicas do Pará, sendo todos egressos da Universidade do Estado do Pará ou da Universidade Federal do Pará, em diferentes 
épocas e, portanto, com currículos diferentes. Tendo ciência disso, inserimos no formulário a pergunta referente à forma de contato com as lutas que esses professores tiveram em suas formações.

Quadro 2. Respostas das questões de formação acadêmica, profissionais e dados pessoais.

\begin{tabular}{|c|c|c|c|c|}
\hline Sujeito & $\begin{array}{l}\text { Teve lutas na } \\
\text { formação }\end{array}$ & $\begin{array}{l}\text { Forma das } \\
\text { lutas na formação }\end{array}$ & $\begin{array}{l}\text { Como utiliza o conteúdo nas } \\
\text { aulas }\end{array}$ & $\begin{array}{l}\text { Benefícios das lutas como } \\
\text { conteúdo }\end{array}$ \\
\hline Professor 1 & Sim & Disciplinas na graduação & $\begin{array}{l}\text { Modalidades específicas com } \\
\text { pouca prática }\end{array}$ & Disciplina e formação do caráter \\
\hline Professora 2 & Sim & Disciplinas na graduação & $\begin{array}{l}\text { Prática corporal, vivências: } \\
\text { força e habilidade }\end{array}$ & Disciplina e respeito \\
\hline Professor 3 & Sim & $\begin{array}{l}\text { Disciplinas na graduação e } \\
\text { oficinas }\end{array}$ & Jogos educativos e vídeos & $\begin{array}{l}\text { Mudança de comportamento, } \\
\text { equilíbrio e valores sociais }\end{array}$ \\
\hline Professora 4 & Sim & $\begin{array}{l}\text { Disciplina de Judô na } \\
\text { graduação }\end{array}$ & Oficinas de capoeira & $\begin{array}{l}\text { Melhora das capacidades físicas, } \\
\text { concentração, força, agilidade, } \\
\text { flexibilidade e aprimoramento } \\
\text { dos movimentos básicos huma- } \\
\text { nos }\end{array}$ \\
\hline Professor 5 & Sim & $\begin{array}{l}\text { Disciplina de Judô e Karatê } \\
\text { na graduação }\end{array}$ & Capoeira com pouca frequência & $\begin{array}{l}\text { Melhora no relacionamento so- } \\
\text { cial, disciplina, respeito, postura } \\
\text { e desenvolvimento cardiorrespi- } \\
\text { ratório }\end{array}$ \\
\hline Professora 6 & Sim & $\begin{array}{l}\text { Disciplina de Judô e Karatê } \\
\text { na graduação }\end{array}$ & Em forma de brincadeiras & Respeito e valores \\
\hline Professora 7 & Sim & $\begin{array}{l}\text { Boxe, Capoeira, Judô e Ka- } \\
\text { ratê na graduação }\end{array}$ & $\begin{array}{l}\text { Jogos recreativos e luta } \\
\text { marajoara }\end{array}$ & $\begin{array}{l}\text { Disciplina, autoconfiança e } \\
\text { respeito mutuo }\end{array}$ \\
\hline Professora 8 & Sim & Disciplina na graduação & $\begin{array}{l}\text { De forma recreativa com } \\
\text { brincadeiras }\end{array}$ & Disciplina e respeito \\
\hline Professora 9 & Sim & Disciplina de Judô & Parceria com academia de boxe & $\begin{array}{l}\text { Disciplina, saída da rotina das } \\
\text { aulas, saúde e cooperação }\end{array}$ \\
\hline Professora 10 & Sim & Disciplina de Judô e Karatê & Apresentação de capoeira & $\begin{array}{l}\text { Amadurecimento, amizade e } \\
\text { interações }\end{array}$ \\
\hline Professor 11 & Sim & Disciplina na graduação & $\begin{array}{l}\text { Formas de jogar capoeira com } \\
\text { a ajuda de alunos que possuem } \\
\text { mais habilidade }\end{array}$ & $\begin{array}{l}\text { Concentração, respeito e } \\
\text { disciplina }\end{array}$ \\
\hline Professora 12 & Não & Sem contato & $\begin{array}{l}\text { Boxe com a ajuda de uma pessoa } \\
\text { de fora da escola com experiên- } \\
\text { cia nas vivências }\end{array}$ & Sem relato \\
\hline
\end{tabular}

Fonte: quadro produzido pelos autores a partir da coleta de dados realizada em 2017.

Dos 12 professores pesquisados, apenas uma não teve contato com as lutas durante a formação universitária e os 11 tiveram esse contato por meio de disciplinas que tratavam o conhecimento das lutas na graduação. Mais da metade desses professores alegaram que o contato que tiveram com a disciplina se deu de forma fragmentada, por meio de modalidades específicas, como o judô, o caratê, o boxe e a capoeira. Tal fato nos leva questionar a forma como essas disciplinas estão sendo ministradas na formação superior em Educação Física, conforme Brandão (2015) constatou ao analisar os currículos das duas instituições nas quais os professores foram formados.

Gomes (2014) alerta para o fato de que, apesar de existirem ementas que orientam a prática do professor na formação em nível superior, o trato com esse conhecimento ainda depende dos interesses do docente, de acordo com suas experiências prévias em alguma modalidade. Brandão (2015) também revelou essa realidade nos cursos de formação em Educação Física das instituições públicas do Pará.

A análise dos Quadros 1 e 2 nos mostra que a maioria dos professores com mais de 10 anos de formação acadêmica, especialmente os mais antigos, são os que relatam o ensino fragmentado em modalidades específicas. Entretanto, ao analisar as ementas das disciplinas, Brandão (2015) mostra que existem contradições nos currículos da formação dos docentes com menos de 10 anos de formação. A principal está nas ementas das disciplinas que conversam com o conhecimento das lutas, pois, ao mesmo tempo que os currículos propõem 
um trato da totalidade, os referenciais teóricos sugeridos apontam para o ensino fragmentado e muito mais voltado para o ensino técnico, o que também foi analisado por Brandão (2015).

Além disso, existem diferenças na forma como o trato do conhecimento é realizado pelos professores na formação acadêmica, também ocorrendo a fragmentação do ensino em modalidades específicas, em decorrência da experiência prévia dos docentes em uma determinada modalidade, conforme também demonstram Gomes (2014) e Brandão (2015).

Outro aspecto constatado por Brandão (2015) e Gomes (2014) é a inexistência de uma correlação entre as modalidades, quando estas são trabalhadas em blocos. Outro destaque é que o ensino acaba sendo voltado para os elementos técnicos, esquecendo-se das dimensões sócio-históricas e dos princípios comuns que aproximam as modalidades. Ou seja, na formação superior, aprende-se a lutar, mas não se aprende como ensinar o conteúdo lutas (GOMES, 2014).

Antunes (2009), em estudo semelhante, ratifica a discussão supracitada, pois alega que, nos cursos de formação superior, os professores das disciplinas de lutas dão ênfase para os elementos técnicos das lutas. Quando as disciplinas, porém, privilegiam somente uma modalidade, Araújo (2015) destaca que essa forma de tratamento leva a uma abordagem restritiva do conhecimento.

Esses determinantes podem fazer com que os professores não dominem as ferramentas didáticometodológicas para levar o trato do conhecimento lutas para a escola. Isso se reflete diretamente na forma como esses professores procederão em suas aulas, possibilidade que necessita ser investigada em estudos futuros. A partir disso, partimos para o terceiro item do Quadro 2, referente aos questionamentos que realizamos com os professores sobre a maneira como eles utilizam o conteúdo, de modo a analisar os reflexos da formação acadêmica em sua prática pedagógica.

O Quadro 2 nos mostra que todos os professores apresentam alguma dificuldade no trato com o conteúdo lutas na escola, pois a maioria demonstra que não possui domínio dos elementos básicos dessas práticas corporais. Três professores participantes da nossa pesquisa apontam para uma terceirização das aulas ou indicam que o conteúdo é ministrado de forma esporádica. Sendo assim, encontramos três categorias referentes às formas de trato do conteúdo lutas na educação básica que possivelmente são reflexos da formação acadêmica inicial desses indivíduos.

A primeira categoria é a terceirização do conteúdo (ensino fragmentado de forma dependente) e fica explícita nas respostas de 4 (quatro) docentes, quando eles relatam parcerias com academias e a colaboração de uma pessoa que possui notório saber em alguma modalidade, seja para auxiliar o professor de educação física, seja para assumir completamente a responsabilidade didática do conteúdo em forma de oficinas ou de apresentações.

A segunda categoria é o caráter de oficinas (ensino fragmentado de forma autônoma) e também aponta a forma rápida como o conteúdo é ministrado. Isso faz com que as lutas tenham um menor espaço nas aulas de educação física, comparada aos outros conteúdos, como o esporte, prática hegemônica nas escolas.

Sobre esses dois aspectos, Fonseca, Franchini e Del Vecchio (2013) afirmam que os docentes trazem especialistas em alguma modalidade de Luta para ministrar o conteúdo, pois não se sentem preparados para esse fim. Além do mais, há pouca ou nenhuma organização do conteúdo da educação física escolar, o que reforça a hegemonia do esporte. É essa falta de domínio que leva os professores a ministrar rapidamente o conteúdo nas raras vezes que os docentes os abordam. Isso fica explícito nas respostas de dois sujeitos que alegam trabalhar o conteúdo com pouca frequência ou pouca prática.

A terceira categoria, com a segunda maior frequência de relatos, refere-se aos jogos e às brincadeiras, que abordam aspectos gerais das lutas, como os princípios comuns. Tal categoria foi apontada por um terço dos docentes (quatro professores) como formas de trabalhar as lutas na escola. O que nos chamou a atenção quanto ao perfil desses docentes é que os mesmos possuem até 10 anos de tempo de serviço, de tal modo que três deles têm apenas três de atuação, ou seja, possivelmente, ainda não sofreram os desgastes advindos da precarização do trabalho docente na educação pública brasileira com a mesma intensidade de outros profissionais da educação com mais tempo de exercício.

O jogo é salientado pela literatura especializada como uma das principais ferramentas para a introdução das lutas no campo escolar. As duas formas de jogo destacadas para o trato das lutas são os jogos de oposição 
(MALDONADO; BOCCHINI, 2013; NASCIMENTO, 2008) e os jogos pré-desportivos (CHAVES; SILVA; MEDEIROS, 2014; MADURO, 2015). É por meio do jogo que se pode dar ênfase aos princípios comuns das lutas, ou seja, para além das modalidades.

Rufino e Darido (2015) classificam-nos como: oposição; regras; imprevisibilidade; simultaneidade das ações de ataque e defesa; contato proposital; alvo móvel; e enfrentamento físico direto. Segundo os autores, é possível, por meio desses princípios, trabalhar os aspectos universais das lutas, que consistem em contextualizar a lógica interna das lutas por elementos comuns a todas as modalidades. Em contrapartida, os outros professores trabalham o conteúdo em modalidades específicas, o que dificulta a compreensão da dinâmica interna das lutas e de seus elementos universais com o aprendizado dos princípios comuns ou princípios condicionais das lutas.

Os docentes também foram questionados quanto aos benefícios provenientes do conhecimento das lutas na escola. Onze dos 12 professores tiveram respostas relacionadas à disciplina e aos valores sociais, como o respeito e a formação do caráter. Isso se deve ao legado das lutas orientais, pois estas são as mais difundidas nacionalmente, como o caratê e o judô.

Em razão dessas duas artes de combate japonesa, a maioria dos docentes afirmou ter estabelecido contato na graduação, outro reflexo da formação dos indivíduos em sua atuação no ambiente escolar. Essa transmissão de valores que os docentes acreditam estarem intrínsecos às lutas não ocorrem de maneira natural, mas dependem da forma como serão trabalhadas (RODRIGUES et al., 2017).

Outros aspectos citados foram referentes às capacidades físicas e à saúde, além da interação social, que auxilia no relacionamento entre os indivíduos, conforme foi explicitado por Rodrigues et al. (2017). Entretanto, observamos que nenhum docente citou benefícios relacionados ao trato de temas como a violência e as questões de gênero, citadas na literatura como eixos em que as lutas possuem forte potencial para problematização (MALDONADO; BOCCHINI, 2013).

\section{CONSIDERAÇÕES FINAIS}

A análise nos mostrou que a grande maioria dos professores teve contato com o conteúdo das lutas durante a formação acadêmica por meio de disciplinas, de tal modo que metade deles teve o contato de forma fragmentada em modalidades sem correlação entre elas e com perspectiva técnica.

Essas implicações podem ter afetado diretamente o trato que os docentes deram para esse conteúdo em sua atuação profissional, pois todos demonstraram alguma dificuldade em ministrar as lutas na escola básica, como a falta de domínio didático-metodológico, gerando, como reflexo de uma formação deficitária, o trato fragmentado em modalidades específicas e a atribuição da responsabilidade didática do conteúdo a terceiros que são especialistas em alguma modalidade. Os resultados também identificaram que os professores que conseguem trabalhar de forma mais próxima ao que é sugerido pela literatura são os com menos tempo de atuação.

Portanto, apresentaram correlação nos Quadros 1 e 2 (respectivamente questões sobre formação acadêmica, profissionais/dados pessoais e questões sobre lutas) as categorias de tempo de formação e de forma de contato com o conteúdo lutas, assim como também de tempo de serviço e da forma como é utilizado o conteúdo. Tais categorias, portanto, nos possibilitaram as principais reflexões deste artigo. Algumas categorias do Quadro 1, a exemplo da idade e do número de escolas em que os professores trabalham, não apresentam correlação com as categorias do Quadro 2, assim como a categoria dos benefícios, localizada no Quadro 2, não apresentou correlação com as categorias do Quadro 1.

Quanto aos benefícios, a maioria dos professores enxerga o aprendizado de disciplina e de valores sociais como as principais vantagens do conteúdo das lutas na educação física escolar, o que demonstra a relevância de esse conhecimento não ser negado na escola. Portanto, é importante para o trato das lutas na educação básica que os docentes estejam preparados para ministrar o conteúdo e essa preparação se inicia na formação superior, o que destaca a importância da qualidade do trato das lutas nos cursos de Licenciatura em Educação Física para gerar reflexos positivos na atuação profissional dos docentes que atuarão nas escolas de ensino básico. 


\section{REFERÊNCIAS}

ANTUNES, M. M. A relação entre as artes marciais e lutas das academias e as disciplinas de lutas dos cursos de graduação em educação física. Lecturas: Educación Física y Deportes, Revista Digital, Buenos Aires, v. 14, n. 139, 2009. Disponível em: <http://www.efdeportes.com/efd139/artesmarciais-e-lutas.htm>. Acessado em: 23 de março de 2018.

ARAÚJO, B. C. L. C. As armas da crítica à crítica das armas: o trato com o conhecimento da categoria luta corporal no currículo de formação de professores de Educação Física da UFS. 2015. 183f. Tese (Doutorado em Educação) - Universidade Federal de Sergipe, São Cristóvão, 2015.

BARDIN, L. Análise de conteúdo. Lisboa: Edições 70, 1977.

BRANDÃO, P. P. S. Lutas no currículo da educação física no ensino fundamental sob o olhar da diversidade cultural: experiências na Escola de Aplicação da Universidade Federal do Pará. 2018. 146f. Dissertação (Mestrado em Currículo e Gestão da Escola Básica) - Universidade Federal do Pará, Belém, 2018.

BRASIL. Ministério da Educação. Secretaria da Educação Básica. Base Nacional Comum Curricular. Brasília. MEC; CONSED; UNDIME, 2017. Disponível em: <http://historiadabncc.mec.gov.br/ documentos/bncc-2versao.revista.pdf>. Acessado em: 01 de março de 2018.

BRASIL. Secretaria de Educação Fundamental. Parâmetros Curriculares Nacionais: introdução aos parâmetros curriculares nacionais. Secretaria de Educação Fundamental. Brasília: MEC/SEF, 1997. $126 \mathrm{p}$.

CHAVES, P. N.; SILVA, I. L.; MEDEIROS, R. M. N. Lutas na educação física escolar: uma experiência no ensino médio. Cadernos de Formação RBCE, Florianópolis, v. 5, n. 2, p. 80-91, 2014.

CORRÊA, A. O.; QUEIROZ, G.; PEREIRA, M. P. V. C. Lutas como conteúdo na educação física escolar. Caraguatatuba: Módulo Centro Universitário, 2010.

FONSECA, J. J. S. Metodologia da pesquisa científica. Fortaleza: UEC, 2002.

FONSECA, J. M. C.; FRANCHINI, E.; DEL VECCHIO, F. B. Conhecimento declarativo de docentes sobre a prática de lutas, artes marciais e modalidades esportivas de combate nas aulas de Educação Física escolar em Pelotas, Rio Grande do Sul. Pensar a prática, Goiânia, v. 16, n. 2, p. 416-34, 2013.

GOMES, M. S. P. O ensino do saber lutar na universidade: estudo da didática clínica nas lutas e esportes de combate. 2014. 205f. Tese (Doutorado em Educação Física) - Universidade Estadual de Campinas, Campinas, 2014.

GOMES, M. S. P. Procedimentos pedagógicos para o ensino das lutas: contextos e possibilidades. 2008. 119f. Dissertação (Mestrado em Educação Física) - Universidade Estadual de Campinas, Campinas, 2008

IBGE. INSTITUTO BRASILEIRO DE GEOGRAFIA E ESTATÍSTICA. Panorama Belém - PA. Disponível em: $<$ https://cidades.ibge.gov.br/brasil/pa/belem/panorama>. Acessado em: 11 de janeiro de 2017.

LOPES, R. G. B.; KERR, T. O. O ensino das lutas na educação física escolar: uma experiência no ensino fundamental. Motrivivência, Florianópolis, v. 27, n. 45, p. 262-79, 2015.

MADURO, L. A. Considerações e sugestões para o ensino das lutas no ambiente escolar. Cadernos de Formação RBCE, Florianópolis, v. 6 n. 2, p. 102-12, 2015.

MALDONADO, D. T.; BOCCHINI, D. As três dimensões do conteúdo na educação física: tematizando as lutas na escola pública. Conexões, Campinas, v. 11, n. 4, p. 195-201, 2013

MARCONI, M. A.; LAKATOS, E. M. Técnicas de pesquisa: planejamento e execução de pesquisas, amostragens e técnicas de pesquisa, elaboração, análise e interpretação de dados. 7. ed. São Paulo: Atlas, 2010.

MENDONÇA, G. P. A.; COSSOTE, D. F.; FERREIRA JÚNIOR, O. N.; RODRIGUES, G. M. Abordagem pedagógica do conteúdo de lutas em curso de licenciatura em educação física nas instituições de ensino superior (IES). Pulsar, Jundiaí, v. 4, n. 1, p. 1-11, 2013. 
MINAYO, M. C. S.; DESLANDES, S. F.; CRUZ NETO, O.; GOMES, R. Pesquisa social: teoria, método e criatividade. 21. ed. Petrópolis: Vozes, 2002.

NASCIMENTO, P. R. B. Organização e trato pedagógico do conteúdo de lutas na educação física escolar. Motrivivência, Florianópolis, v. 20, n. 31, p. 36-49, 2008.

NASCIMENTO, P. R. B.; ALMEIDA, L. A tematização das lutas na educação física escolar: restrições e possibilidades. Movimento, Porto Alegre, v. 13, n. 3, p. 91-110, 2007.

RODRIGUES, A. L. C.; BAIÃO JÚNIOR, A. A.; ANTUNES, M. M.; ALMEIDA, J. J. G. Percepção dos dirigentes das escolas do município de Jaguariúna sobre as lutas. Journal of Physical Education, Maringá, v. 28, n. 1, p. 1-14 (e2809), 2017.

RUFINO, L. G. B. "Campos de luta”: o processo de construção coletiva de um livro didático na educação física no ensino médio. 2012. 355f. Dissertação (Mestrado em Desenvolvimento humano e tecnologias) - Universidade Estadual Paulista, Rio Claro, 2012.

RUFINO, L. G. B.; DARIDO, S. C. O ensino de lutas na escola: possibilidades para a educação física. Porto Alegre: Penso, 2015.

SILVA, R. P. G. Uma abordagem metodológica para o trato pedagógico da luta nos cursos de formação de professores de educação física. 2013. 213f. Dissertação (Mestrado em Educação Física) - Universidade Federal do Rio Grande do Norte, Natal, 2013.

Autor correspondente: Marcio Antonio Raiol dos Santos

E-mail: marsraiol@gmail.com

Recebido: 13 de fevereiro de 2018.

Aceito: 23 de abril de 2018. 